knowledge into the possible, from the definite to the indefinite, which, later, is to become more definite and a stage for further advance. Mickle was a careful observer and a most indefatigable collector and recorder, but his collection of facts was so general as to be rather a heap than an arranged group. He toiled, but he hardly constructed. And now he has left very many valuable collections, from which others may select. Born in a colony, living his life in the Mother-country, when failing in general and mental health he returned to die in his home colony.

\title{
Bibliography.
}

Fournal of Mental Science.-Vol. XVIII, "Temperature in G.P." XIX, " Digitalis in Mania." XX, "Case of Ataxic Aphasia." XXI, "Case of G.P., with Autopsy." XXIII, "Unilateral Sweating in G.P."; "Syphilis and G.P." XXIV "Varieties of G.P." XXV, "Syphilis and Mental Alienation." XXVI, "G.P." XXVIII, "Cerebro-Spinal Localisation"; "G.P. from Cranial Injury"; " Hallucinations in G.P."; "Knee-jerk in G.P." ' XIX, "Tubercular Meningitis in Insane Adult"; "Unilateral Sweating"; "Visceral Syphilitic Lesions in Insane free from Cerebral Syphilis." XXX, "Pathological Specimens of Heart and Brains"; "Rectal Feeding and Medication"; "Brain Disease of Traumatic Origin"; "Spinal Sclerosis following Brain Lesion"; "Cerebral Localisation"; XXXII, "G.P. Digest"; "Abnormal Forms of Breathing." XXXIV, "Antifebrin in Pyrexia "; "Insanity in Relation to Heart and Lung Disease."

Brain.-Vol. III, "Review on G.P." V, "Blindness and Cerebral Atrophy." X, "Syphilis and G.P." XII, "Aortic Aneurysm and Insanity"; "Katatonia." XIV, "Katatonia, with Autopsy." XV, "Traumatic Factor in Mental Disease." XVII, "G.P. Digest." XVIII, "Syphilis of the Nervous System." XXI, "Nervous Syphilis, Digest."

Hack Tuke's Dictionary of Psychological Medicine.- "Sunstroke and General Paralysis," "Temperature in General Paralysis," "Association of Mental and Cardiac Disease," "Pupillary Signs in G.P.I.," "Antifebrin," "Digitalis in Insanity," "Spinal Durhæmatomata in G.P.," "G.P. following Rheumatic Affections," "Diagnosis of Post-febrile Paralysis," "Treatment of Acute Mania," "Traumatic Factor in Mental Disease."

G. H. S.

\section{William Graham.}

DeAth, in these latter days, brings few surprises. It is with numbed emotions that we accept the daily sacrifice of our best; yet, even thus environed, the swift passing of William Graham seemed unbelievable. No personality was less suggestive of mortality; no man went his way less conscious of the suspended sword. Independent, fearless, and untiring, he planned and worked without thought of untoward interruption; and as he lay on his death-bed he was meditating, and writing of, large schemes of travel and research, to be undertaken when his practical work for the insane should be ended.

William Graham was born at Dundrod, in the Co. Antrim, on November 25th, 1859. He was educated in the Queen's College, Belfast; obtained the M.D. degree of the old Royal University of Ireland in 1882, and became L.R.C.S. of Edinburgh in the following year. Specialised study in London and on the Continent resulted in his appointment in April, 1884, as Assistant Medical Officer at the Belfast District Asylum. In the December of 1886 he was appointed Resident Medical Superintendent of the Armagh District Asylum, being then probably the youngest superintendent in the United Kingdom. The latter appointment owed nothing to influence in high places. William Graham was selected on his observed merits to fill a troublesome post; a choice which he more than justified.

The Armagh Asylum, under Dr. Graham, inaugurated in Ireland a high standard of internal equipment, and when his ten years' service there ended the inspectors devoted more than two pages of their annual report to an enumeration of the substantial and permanent improvements effected under his rule-a tribute as well-deserved as it was exceptional.

In the autumn of 1897 he received further promotion, returning to the Belfast Asylum as Superintendent, and there found ample scope for his large activities. The Belfast Asylum was built in the year 1829 for 104 patients, and was subsequently 
enlarged to 400 beds, while at this time the asylum population had risen to over 700. To meet this pressure the Governors had recently purchased, but had not begun to develop, an estate of 295 (now over 400) acres at Purdysburn, a few miles outside Belfast. The new Superintendent saw his opportunity, and followed it up with characteristic enthusiasm. His plans were accepted and liberally executed by a progressive asylum committee, and the product is the Purdysburn Villa Colony - nearly, but not quite, completed. For twenty strenuous years he combined the duties of superintendent with personal supervision of every detail in the construction of the new villa colony. This is not the place or moment for any description of his achievement. The colony has been visited by many members of the Association and is recognised as perhaps the best that has been done for the insane poor in the United Kingdom. In recreation the doctor was as energetic as in work. He took his rest on horseback, in the hunting-field, or on the polo-ground.

No fitter memorial can be raised to William Graham than the continuation of the colony as he designed it. Ireland, in these matters, has fallen somewhat back in the race; and one hopes that, for example and encouragement, the original design of the model villa colony will be worthily completed.

The successful superintendent, the creator of the model villa colony, was sufficiently-well known, though he shunned publicity and made no bid for professional or popular fame. There was another William Graham whose acquaintance was made with difficulty; not so much from conscious reserve on his part, but because this other personality, was accessible only in moments of comparative repose, and such moments were rare. In his speculative moods he was the best of companions and conversationalists; ready either to talk or to listen, and never dogmatising. He was profoundly interested in every branch of psychology; his study was of the mind in apparent health, as well as of the mind disordered. The particular mental twists which determine humanity to its divergent opinions and beliefs, aspirations and negations, were of unceasing interest. A man of few prejudices and no intolerances, he postulated no categories of the impossible or the incredible. His attitude was consistently that of student and observer. An evening of talk over the fire at Purdysburn House was a realisation of Stevenson's aphorism: "The tendency of all living talk draws it back and back into the common focus of humanity."

He was inevitably attracted by the theories of Freud, and put them on trial in asylum practice, but the analysis practised by Graham did not conspicuously recall the distinctive hypothesis of Freudism round which controversy has gathered. In the early summer of 1914 he started on an expedition to the South Sea Islands, " to see," as he put it, " mankind in the rough." The outbreak of war closed the route to the South Sea, but he was enabled to view humanity in various development over a great portion of the globe.

During the last few months of his life he undertook additional responsibilities as Lieutenant-Colonel in command of the new war hospital now occupying the buildings of the old Belfast Asylum. The inevitable routine and clerical duties were in many details uncongenial, but success, as usual, attended his true professional work, to the very great benefit of his soldier patients.

He died on November 5th, 1917. A slight accident had caused fracture of the femur, and the sudden and unexpected end resulted from an embolism occurring while he lay disabled. He was fortunate in his death. Pain he could have borne, but not easily the gradual failures of old age.

"To believe in immortality is one thing, but it is first needful to believe in life."

William Graham "believed in life."

\section{Dr. Henry Maudsley.}

We regret to have to record the recent death of Dr. Henry Maudsley. Owing to limitations of space an obituary notice of our late colleague must be deferred till the April number of the Journal. 